\title{
Analysis of membraneless microfuel cell using decomposition of hydrogen peroxide in a Y-shaped microchannel
}

\author{
Falin Chen $^{a}$, Min-Hsing Chang ${ }^{b}$, , Chia-Wei Hsu ${ }^{a}$ \\ a Institute of Applied Mechanics, National Taiwan University, Taipei 107, Taiwan, ROC \\ ${ }^{\mathrm{b}}$ Department of Mechanical Engineering, Tatung University, Taipei 104, Taiwan, ROC \\ Received 18 March 2007; received in revised form 19 May 2007; accepted 29 May 2007 \\ Available online 7 June 2007
}

\begin{abstract}
A theoretical analysis has been performed in this study for a novel design of membraneless microfuel cell utilizing a Y-shaped microchannel. Hydrogen peroxide is employed both as fuel and oxidant and dissolved in dilute sodium hydroxide and sulfuric acid solutions, respectively. The anode and cathode liquid streams enter the Y-shaped microchannel separately at different inlets and then flow in parallel through the microchannel without occurrence of turbulent mixing on the contact interface of both streams. The decomposition of hydrogen peroxide in both streams will generate electric power. Such a novel design eliminates the need of a membrane to partition the two liquid streams. The cell performance was investigated in detail by examining the important system parameters such as the concentration of reactant, volumetric flow rate, thickness of catalytic layer, length of microchannel, and geometric design of electrodes. Results provide physical insights for the effects of these parameters on the cell performance and benefit the optimal design of this type of microfuel cell as well as the fulfillment of its application in portable power sources.
\end{abstract}

(C) 2007 Elsevier Ltd. All rights reserved.

Keywords: Membraneless microfuel cell; Hydrogen peroxide; Y-shaped microchannel

\section{Introduction}

Miniature fuel cells have received much attention in the literature due to its promising applications in portable power sources and MEMs related devices such as "Lab-on-a-chip" systems [1-16]. Their applications in these devices require high energy density and the performance should be comparable to that of large systems. In general, among the existing types of fuel cells, proton exchange membrane fuel cell (PEMFC) [1,2] and direct methanol fuel cell (DMFC) $[3,4]$ are considered to be suitable candidates for miniature fuel cells because of their low operating temperature, high power density, and feasibility for miniaturization. While recently, a novel design of miniature fuel cell based on microfluidic devices has emerged as another type of miniature fuel cells. This microfuel cell utilizes the nature of laminar flow in a Y-shaped microchannel at low Reynolds number [17]. Both anode and cathode liquid streams flow in parallel through the

\footnotetext{
* Corresponding author. Tel.: +886 225925252x3410; fax: +8862 25997142. E-mail address: mhchang@ttu.edu.tw (M.-H. Chang).
}

microchannel without turbulent mixing appearing on the interface of both streams. Such a novel design removes the membrane used in conventional PEMFC and DMFC, and possesses many merits: the ohmic losses and fouling problems due to the membrane are eliminated, the fabrication and water management are simpler, the size of fuel cell can be greatly reduced, and the liquid fuel has higher energy density which is particularly important in the applications of portable power sources.

Many experimental studies had been performed in developing membraneless microfuel cells. A variety of fuels were used in these investigations such as formic acid, methanol, and hydrogen solutions. However, since they all used oxygen solution as the oxidant, the performance of these microfuel cells was found to be restricted severely by the low transport efficiency of oxygen in the cathode stream. Recently, an experimental study using hydrogen peroxide has been proposed for a Y-shaped microchannel fuel cell [14]. The hydrogen peroxide is used not only as a reductant but also as an oxidant. The decomposition of hydrogen peroxide in anode and cathode streams can generate electric power which is comparable to a typical air-breathing DMFC at room temperature, and produce no carbon dioxide 
emission. Furthermore, the hydrogen peroxide possesses many merits in comparison with the other fuels: good environmental safety, simple fuel storage, and good cost efficiency. Therefore, it is quite important to understand the characteristics of this type of membraneless microfuel cell. In this study, we have developed a theoretical model to simulate this membraneless Yshaped microchannel fuel cell and performed a numerical study to investigate the critical factors which may significantly affect the cell performance. The effects of species transport and geometrical design of electrodes are also examined in detail. The results provide physical insights for the characteristics of transport phenomena and electrochemistry reactions in this microfuel cell system,

\section{Theoretical model and formulation}

The top view of the membraneless Y-shaped microfuel cell is shown in Fig. 1(a) and the cross-sectional view of the main channel is shown in Fig. 1(b). Both fuel and oxidant streams enter the system at two separate inlets, and then merge and flow in parallel through the microchannel. The system dimensions are indicated in both figures which are the same as those used in the experimental study [14]. Here we employ hydrogen peroxide as reductant and also oxidant. A dual acid/alkaline electrolyte is used in which the electrolyte consists of sulfuric acid and sodium hydroxide solutions. In general, under the assumption

(a)

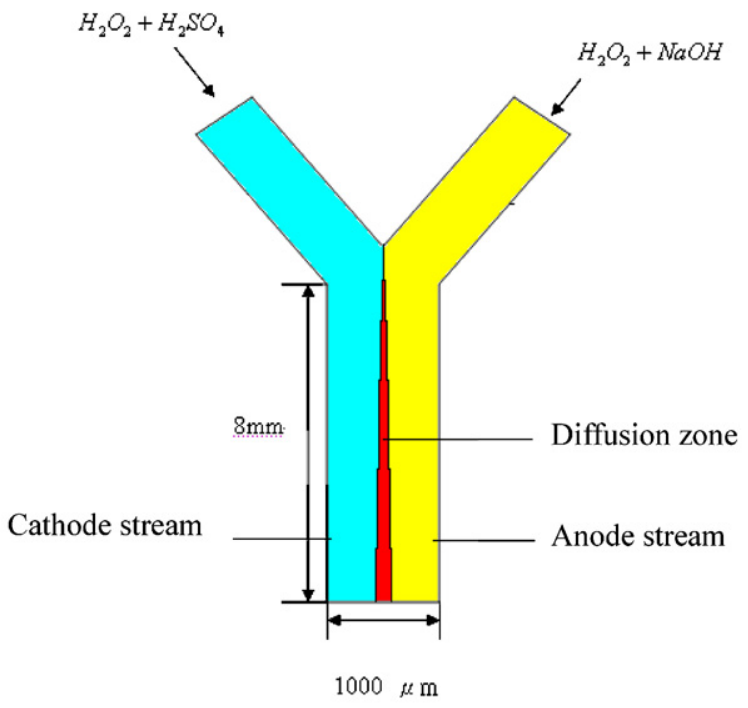

(b)

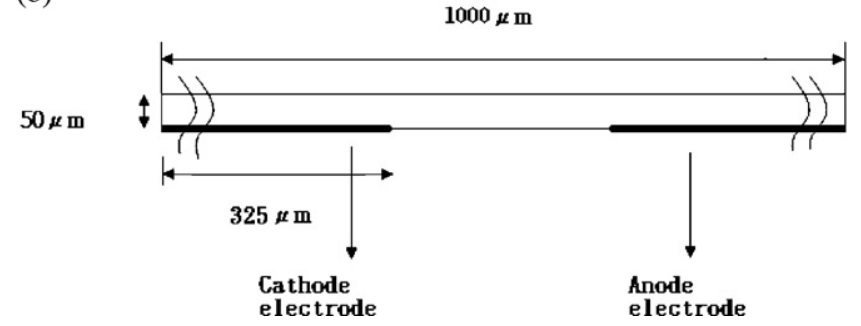

Fig. 1. Schematic diagrams of system configuration: (a) top view and (b) crosssectional view of main microchannel. of natural laminar flow within the microchannel, a mixing zone will gradually appear down the stream due to the diffusive effect of reactants along the contact interface between both streams. In addition, both anode and cathode catalyst layers are coated on the bottom substrate as shown in Fig. 1(b). It is assumed that electrochemical reactions occur in these layers only. In the anode side, the hydrogen peroxide will react with $\mathrm{OH}^{-}$ions and proceed in two steps, the first one is

$\mathrm{H}_{2} \mathrm{O}_{2}+\mathrm{OH}^{-} \rightarrow \mathrm{HO}_{2}^{-}+\mathrm{H}_{2} \mathrm{O}$

The ions $\mathrm{HO}_{2}{ }^{-}$will react further with $\mathrm{OH}^{-}$and result in the second electron-losing reaction below:

$\mathrm{HO}_{2}^{-}+\mathrm{OH}^{-} \rightarrow \mathrm{O}_{2}+\mathrm{H}_{2}+2 \mathrm{e}^{-}$

where the standard reduction potential $E^{0}$ of this reaction is $0.0649 \mathrm{~V}$. While in the cathode side, the hydrogen peroxide will react with ions $\mathrm{H}^{+}$in the acid electrolyte together with the electrons from the anode reaction through an external circuit in the form:

$\mathrm{H}_{2} \mathrm{O}_{2}+2 \mathrm{H}^{+}+2 \mathrm{e}^{-} \rightarrow 2 \mathrm{H}_{2} \mathrm{O}$

where the corresponding value of $E^{0}$ is $1.763 \mathrm{~V}$. Both half reactions (2) and (3) can be combined to generate electricity in such a dual-electrolyte system and the overall electrochemical reaction together with reaction (1) becomes

$2 \mathrm{H}_{2} \mathrm{O}_{2}+2 \mathrm{H}^{+}+2 \mathrm{OH}^{-} \rightarrow 4 \mathrm{H}_{2} \mathrm{O}+\mathrm{O}_{2}$

where the theoretical electromotive force of this reaction should be $1.828 \mathrm{~V}$. More detailed reaction mechanisms in this system can be found in Ref. [18]. This value seems to be obviously higher than that of conventional PEMFC or DMFC. However, the decomposition of $\mathrm{H}_{2} \mathrm{O}_{2}$ on the surface of catalyst will cause a significant activation loss which makes the practical output of open circuit voltage reduce greatly. Besides, the consumption of $\mathrm{OH}^{-}$ions in anode side will make the $\mathrm{SO}_{4}{ }^{2-}$ ions in cathode stream diffuse through the contact interface to neutralize the anode stream, and vice versa for the $\mathrm{Na}^{+}$ions. The products of the overall reaction thus contain water, oxygen, and salt but without $\mathrm{CO}_{2}$ emission. Accordingly, such a novel design is regarded to be more environmentally friendly than the DMFC.

In order to simplify the simulation model, the flows within the microchannel are assumed to be isothermal, incompressible, and remain in steady laminar flow regime. A theoretical model which is similar to that of Chen et al. [16] is then developed to simulate the system. Here we will interpret the developed model briefly. In both liquid streams, the transports of mass, momentum, and concentration of reactants are defined, respectively by the general continuity equation, Navier-Stokes equation, and Fick's law. In the catalyst layers, the electrodes are assumed to be isotropic porous materials with effective solid-phase conductivities defined by the Bruggeman-type relation with tortuosity 1.5 [19]. Accordingly, the concentration equations in these layers can be expressed by

$u_{j} \frac{\partial C_{i}}{\partial x_{j}}=D_{i} \Delta C_{i}+\frac{e_{i}}{n F} S_{i}$, 
where the subscript $i$ represents the reactant species, $u_{j}$ the velocity component with $j=1-3, C$ the concentration, $D$ the diffusion coefficient, $\Delta$ the Laplacian operator, $e$ the mole number, $n$ the number of electrons transferred in the reaction, $F$ the Faraday constant, and $S$ is the rate of electrochemical reaction in terms of the volumetric rate of current generation with unit $\mathrm{A} \mathrm{m}^{-3}$. Moreover, the electric potential $\Phi$ in this system can be defined by

$\sigma_{i} \Delta \Phi_{i}=S_{i}$

where the electric conductivity $\sigma$ is assumed to be a constant. The reaction rate $S_{i}$ is zero everywhere in the system except in the catalyst layers and is related to the concentrations of reactants by the Bulter-Volmer equation:

$S_{i}=a j_{0}\left(\frac{C_{i}}{C_{i}^{0}}\right)^{\beta_{i}}\left[\exp \left(\frac{\alpha n F}{R T} \eta\right)-\exp \left(-\frac{(1-\alpha) n F}{R T} \eta\right)\right]$,

where $a$ is the density of the catalyzed active area on the electrode, $j_{0}$ the exchange current density at the reference reactant concentration $C_{i}^{0}, C_{i}$ the concentration of species $i, \beta_{i}$ the reaction order, $\alpha$ the charge transfer coefficient, $R$ the universal gas constant, $T$ the absolute temperature, and $\eta$ is the overpotential. After solving the theoretical model, the current density vector $\mathbf{j}$ can be determined by

$j_{i}=-\sigma \frac{\partial \Phi}{\partial x_{i}}$.

Here only the component normal to the electrode surface will contribute to the output of electricity from the system. The commercial CFD package, CFD-ACE+, was employed in this investigation to perform the numerical simulation. The system was first discretized with structured grids and then solved by the upwind scheme based on the finite volume method. In order to make sure the numerical accuracy and obtain converged results, several grid tests had been performed and the total grid number was determined by an appropriate consumption of CPU time.

\section{Results and discussion}

The numerical results are first compared with those of experimental study [14]. In the anode stream, the electrolytes were supposed to be prepared with the concentration ratio $\left[\mathrm{H}_{2} \mathrm{O}_{2}\right] /[\mathrm{NaOH}]=1$. While in the cathode stream the $\mathrm{H}_{2} \mathrm{O}_{2}$ solutions were kept with the concentration ratio $\left[\mathrm{H}_{2} \mathrm{O}_{2}\right] /\left[\mathrm{H}_{2} \mathrm{SO}_{4}\right]=2$. Four typical cases, $\left[\mathrm{H}_{2} \mathrm{O}_{2}\right]=0.1 \mathrm{M}$, $0.22 \mathrm{M}, 0.45 \mathrm{M}$, and $0.75 \mathrm{M}$, are considered here and the corresponding properties of these solutions are given in Table 1 [20]. The inlet velocity is $0.96 \mathrm{~m} / \mathrm{s}$ which is equivalent to the Reynolds number 90 approximately based on the hydraulic diameter of the main microchannel. Note that the laminar flow generally occurs in a microchannel when the Reynolds number is less than 200. Therefore, it should be a reasonable assumption to simulate the flow within laminar flow regime. As shown in Fig. 2, it is found that the numerical results are in good agreement with previous experiments [14]. The results also indicate that
Table 1

The parameters used in the computations

\begin{tabular}{lrr}
\hline$\left[\mathrm{H}_{2} \mathrm{O}_{2}\right]$ & Anode stream & Cathode stream \\
\hline $0.1 \mathrm{M}$ & & \\
Conductivity $(\mathrm{mho} / \mathrm{m})$ & 2.00 & 1.15 \\
Kinematic viscosity $\left(\mathrm{m}^{2} / \mathrm{s}\right)$ & 1.03 & 1.01 \\
Density $\left(\mathrm{kg} / \mathrm{m}^{3}\right)$ & 1001.58 & 1001.61 \\
$0.22 \mathrm{M}$ & & \\
Conductivity (mho/m) & 4.27 & 5.11 \\
Kinematic viscosity $\left(\mathrm{m}^{2} / \mathrm{s}\right)$ & 1.05 & 1.03 \\
Density $\left(\mathrm{kg} / \mathrm{m}^{3}\right)$ & 1003.48 & 1003.54 \\
$0.45 \mathrm{M}$ & & \\
Conductivity $(\mathrm{mho} / \mathrm{m})$ & 8.36 & 9.97 \\
Kinematic viscosity $\left(\mathrm{m}^{2} / \mathrm{s}\right)$ & 1.11 & 1.05 \\
Density $\left(\mathrm{kg} / \mathrm{m}^{3}\right)$ & 1007.11 & 1007.00 \\
$0.75 \mathrm{M}$ & & 1.08 \\
Conductivity $(\mathrm{mho} / \mathrm{m})$ & 13.21 & 1012.06 \\
Kinematic viscosity $\left(\mathrm{m}^{2} / \mathrm{s}\right)$ & 1.18 & \\
Density $\left(\mathrm{kg} / \mathrm{m}^{3}\right)$ & 1011.85 & \\
\hline
\end{tabular}

the cell performance depends heavily on the concentration of hydrogen peroxide. For the case $\left[\mathrm{H}_{2} \mathrm{O}_{2}\right]=0.75 \mathrm{M}$, the maximum power density can reach about $24 \mathrm{~mW} / \mathrm{cm}^{2}$, which is comparable to the air-breathing DMFC and also greatly larger than the other designs of membraneless microfuel cell $[6,9,12]$. Therefore, such a novel design appears to have higher potential to be utilized in portable power sources.

In order to understand the characteristics of this microfuel cell, the effects of several system parameters on the cell performance are examined in sequence. We first explore the effects of volumetric flow rate and the results are demonstrated in Fig. 3. Obviously, the cell performance can be improved by a higher flow rate. However, this effect seems to decay rapidly and the polarization curve eventually becomes invariant once the flow rate is high enough. The main reason causes this phenomenon can be explained by examining the concentration profile of ion $\mathrm{H}^{+}$at the outlet of microchannel as shown in Fig. 4. When the flow rate is $1.0 \mathrm{ml} / \mathrm{min}$ in Fig. 4(a), one can see that the mixing

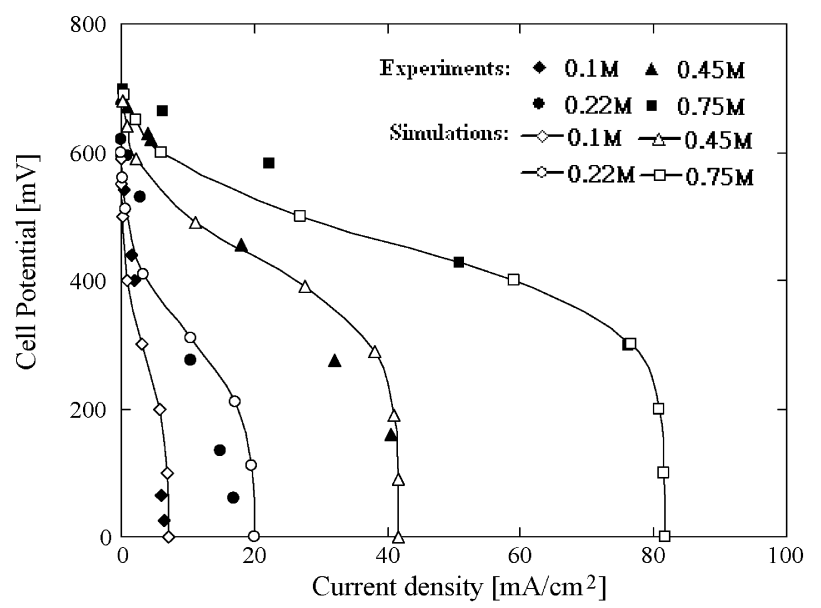

Fig. 2. The variations of $I-V$ curves for four assigned concentrations of hydrogen peroxide. The results are compared with the experimental data of Hasegawa et al. [14]. 


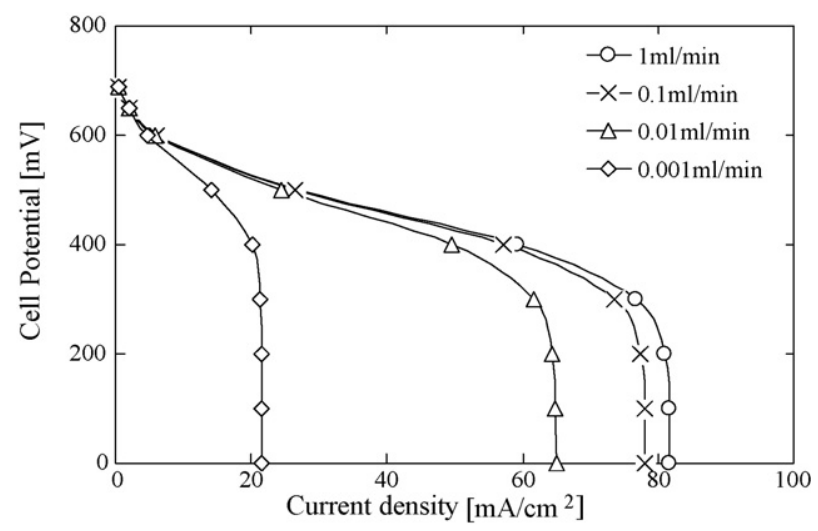

Fig. 3. The $I-V$ curves for four assigned volumetric flow rates with $\left[\mathrm{H}_{2} \mathrm{O}_{2}\right]=0.75 \mathrm{M}$.

zone in the central part of the microchannel where the neutralization reaction occurs is quite narrow. As the flow rate decreases, both anode and cathode streams have more time to be in contact with each other and thus enhance the diffusion effect on the interface. Therefore, the mixing zone gradually becomes wider as indicated in Fig. 4(b)-(d). The extension of mixing zone results in serious fuel crossing phenomenon especially in the low flow rate case as shown in Fig. 4(d). Consequently, the cell performance reduces greatly. A concentration boundary layer which indicates the depletion zone of reactant also can be observed in the left cathode stream as shown typically in Fig. 4(c). A thicker depletion zone will produce higher transport resistance and hinder the reactant to reach the reacting surface. Obviously, a higher flow rate will suppress the development of concentration boundary layer and its thickness at the outlet becomes thinner as shown in Fig. 4(a) and (b). This factor also produces a significant influence to make the cell performance increase with the flow rate.

Fig. 5 demonstrates the variations of limiting current density $I_{1}$ with flow rate $Q$ for the four typical cases. One can see that in each case the limiting current density always rises rapidly with

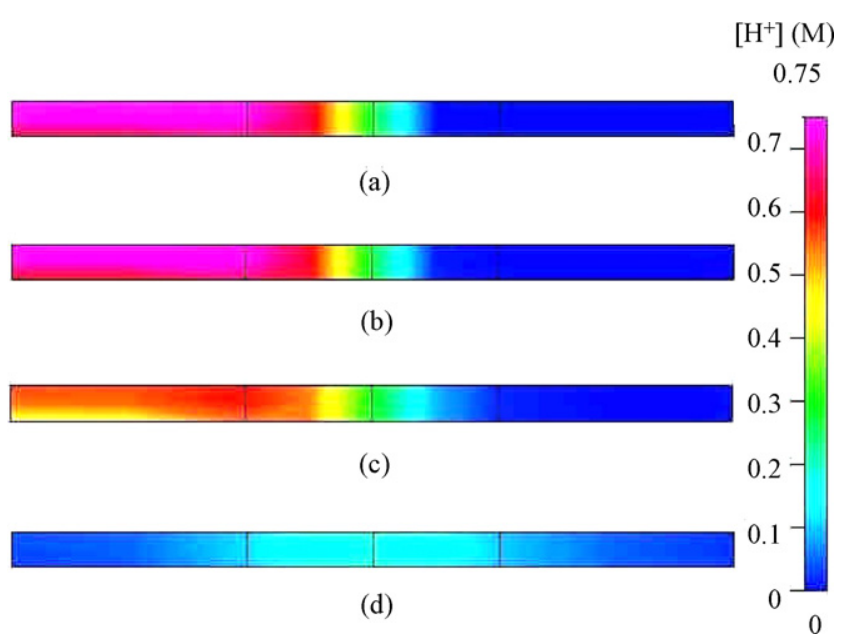

Fig. 4. The concentration contours of ion $\mathrm{H}^{+}$at the outlet of microchannel for four assigned flow rates with $\left[\mathrm{H}_{2} \mathrm{O}_{2}\right]=0.75 \mathrm{M}$ and cell potential $0.3 \mathrm{~V}$ : (a) $1.0 \mathrm{ml} / \mathrm{min}$, (b) $0.1 \mathrm{ml} / \mathrm{min}$, (c) $0.01 \mathrm{ml} / \mathrm{min}$, and (d) $0.001 \mathrm{ml} / \mathrm{min}$.

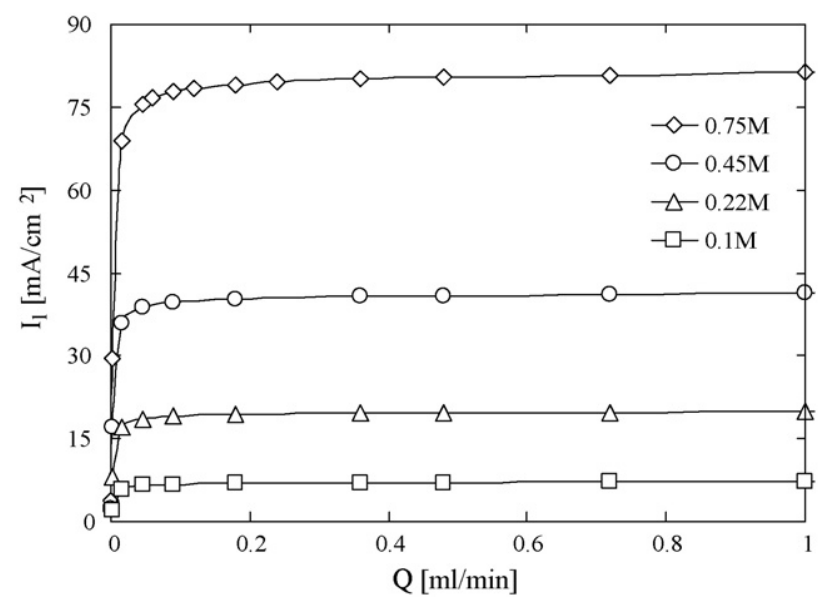

Fig. 5. The variations of limiting current density $I_{1}$ with volumetric flow rate $Q$ for four assigned concentrations of hydrogen peroxide.

the flow rate and then tends to be a constant eventually. This result reveals that a sufficient strength of flow rate is enough for the system, while an excessive flow rate is not necessary and may increase the parasitic power consumption from the cell itself causing a reduction of available power output. Note that the power required for driving the flow can be estimated from the mean flow velocity and mass flow rate. In the case of volumetric flow rate $1.0 \mathrm{ml} / \mathrm{min}$, the parasitic power loss is approximately $0.02 \mathrm{~mW}$ only and even smaller for lower flow rate. Relative to the total power $0.6 \mathrm{~mW}$ generated typically at power density $20 \mathrm{~mW} / \mathrm{cm}^{2}$, the present microfuel cell system should be able to generate enough power to drive the fluid motion by itself. However, since the available liquid micro-pump is generally in the order of $1 \mathrm{~mW}$, a multi-channel design should be necessary in practical application.

The consumption rate of reactant is also an important property of the system and the results are shown in Fig. 6 . The consumption rate of hydrogen peroxide $\lambda$ is defined by

$\lambda=\frac{\dot{m}_{\mathrm{i}}-\dot{m}_{\mathrm{e}}}{\dot{m}_{\mathrm{i}}} \times 100 \%$,

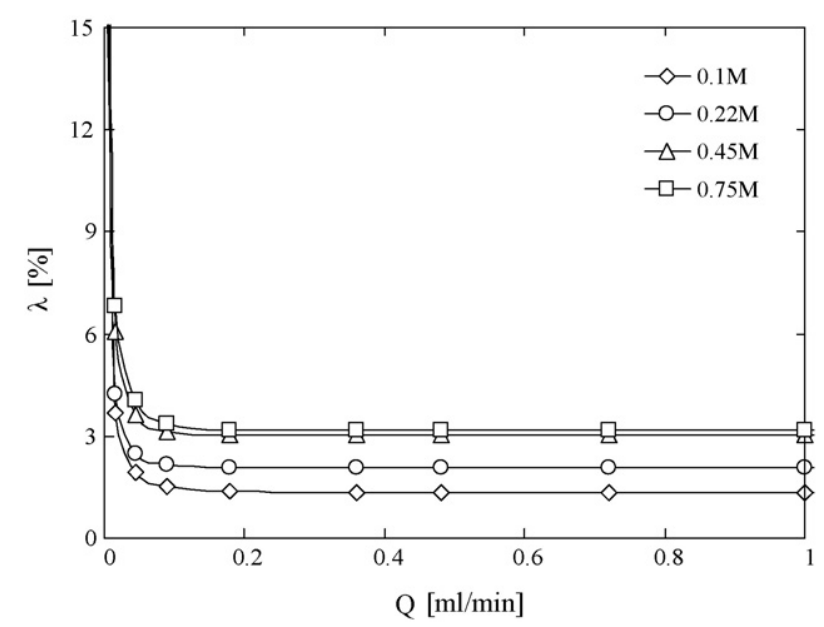

Fig. 6. The variations of consumption rate of hydrogen peroxide $\lambda$ with volumetric flow rate $Q$ for four assigned concentrations of hydrogen peroxide. 
where $\dot{m}_{\mathrm{i}}$ and $\dot{m}_{\mathrm{e}}$ are respectively the mass flow rate of hydrogen peroxide at the inlet and outlet of the microchannel. As seen in this figure, the consumption rate of each case also becomes invariant after the magnitude of volumetric flow rate exceeds about $0.1 \mathrm{ml} / \mathrm{min}$. For a fixed flow rate, the value of $\lambda$ increases with the concentration of reactant but also gradually approaches a constant. In the present system structure, the values of $\lambda$ are always less than $4 \%$ for all the four typical cases as the flow rate is greater than $0.1 \mathrm{ml} / \mathrm{min}$. It is worth of noting that the definition of $\lambda$ is equivalent to the fuel utilization efficiency $\varepsilon_{\mathrm{f}}$. For a fuel cell, the real efficiency is calculated by

$\varepsilon_{\text {real }}=\varepsilon_{\mathrm{t}} \times \varepsilon_{\mathrm{v}} \times \varepsilon_{\mathrm{f}}$,

where $\varepsilon_{\mathrm{t}}$ is the reversible thermodynamic efficiency defined by the ratio of the Gibbs free energy change to the enthalpy change, and $\varepsilon_{\mathrm{V}}$ is the voltage efficiency defined by the ratio of the real operating voltage to the reversible cell voltage. A detailed discussion for $\varepsilon_{\mathrm{t}}$ has been given in Ref. [14], in which the reversible thermodynamic efficiency $\varepsilon_{\mathrm{t}}$ was found to be $128 \%$ because the entropy change $\Delta s$ of the overall reaction is positive which means the system may convert the term $T \Delta s$ into electricity. Whereas other fuel cells generally waste this term as heat. However, under the same voltage efficiency $\varepsilon_{\mathrm{v}}$, the low fuel utilization efficiency of the present system makes the real efficiency just in the same order as other fuel cells or even smaller. Thus, how to raise the consumption rate becomes a critical issue in the system design. A feasible way is to increase the reaction area by changing the design of electrode position. This result will be discussed later.

The catalyst layer also plays an important role in the factors affecting the system performance. Here we consider the thickness effect only and separately examine the influences of anode and cathode catalyst layers. The results are shown in Fig. 7(a) and (b), respectively. As seen in Fig. 7(a), the cell performance can be improved significantly by an increase of thickness of anode catalyst layer. Similar phenomena also can be observed in the cathode side as shown in Fig. 7(b) and the improvements are more pronounced. These characteristics are quite different from those observed in the other types of membraneless microfuel cell such as those employed formic acid as the fuel and oxygen solution as the oxidant [6-8]. In these designs the cell performance was found to be dominated primarily by the cathode catalyst layer, while the anode catalyst layer plays no role in the factors affecting the cell performance. The main reason is that the diffusivity of solute oxygen in liquid is quite low and induces high transport resistance in the cathode stream. But in the present system, both reductant and oxidant are the same in both anode and cathode streams, resulting in the distinct influence of anode catalyst layer on the cell performance, while the cathode catalyst layer still produces a more significant effect.

As we have discussed that the mixing zone in the central part of the microchannel will grow gradually down the stream, a longer microchannel will produce more total output of electricity, but the fuel crossing might become more serious at the outlet location. To examine this effect, we lengthen the microchan-
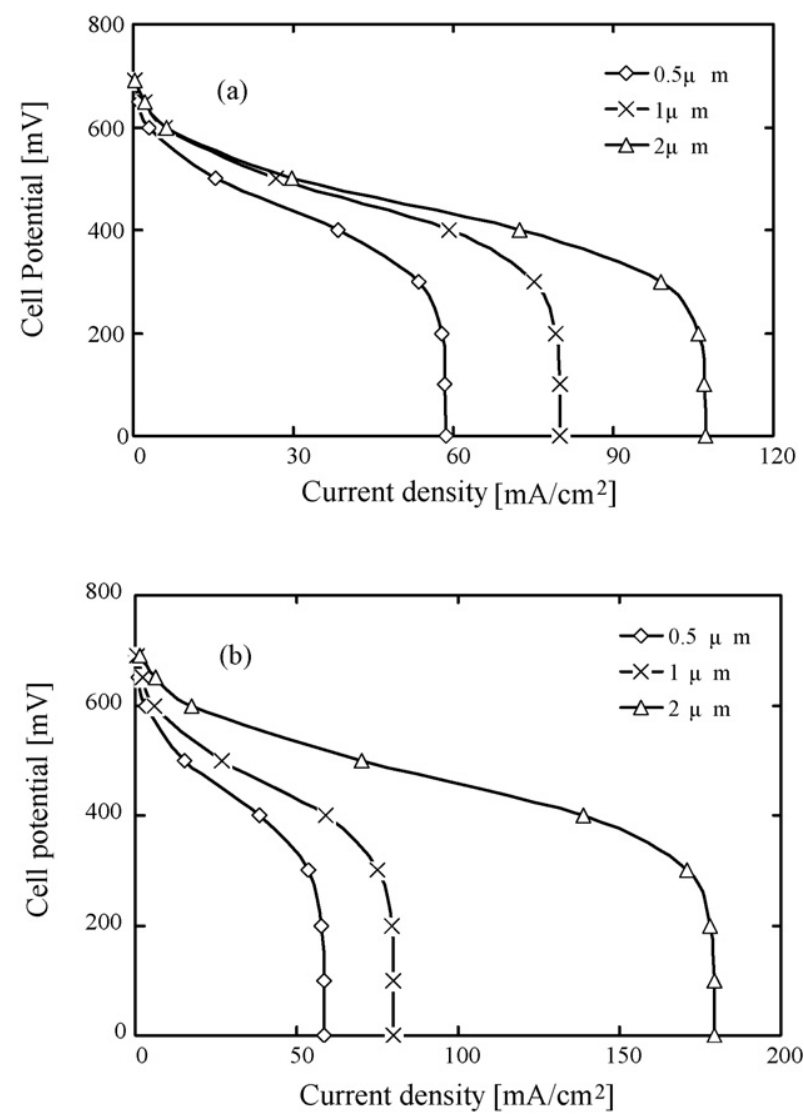

Fig. 7. The $I-V$ curves for three assigned thicknesses of catalyst layer with $\left[\mathrm{H}_{2} \mathrm{O}_{2}\right]=0.75 \mathrm{M}$ and $Q=0.36 \mathrm{ml} / \mathrm{min}$ : (a) $h_{\mathrm{c}}=1.0 \mu \mathrm{m}$, and $h_{\mathrm{a}}=0.5,1.0$, and $2.0 \mu \mathrm{m}$; (b) $h_{\mathrm{a}}=0.1 \mu \mathrm{m}$, and $h_{\mathrm{c}}=0.5,1.0$, and $2.0 \mu \mathrm{m}$; where $h_{\mathrm{a}}$ and $h_{\mathrm{c}}$ are the anode and cathode thicknesses of catalyst layer, respectively.

nel length and utilize the concentration profile of ion $\mathrm{H}^{+}$at the outlet to indicate the mixing zone region. The results are demonstrated in Fig. 8(a) and (b) for three assigned microchannel lengths. As demonstrated in Fig. 8(a), the volumetric flow rate is $0.09 \mathrm{ml} / \mathrm{min}$ and under such a low flow rate the mixing zone indeed extends gradually with the microchannel length as well as the concentration boundary layer adjacent to the surface of cathode electrode. In contrast to this low flow rate case, the volumetric flow rate is increased to $0.36 \mathrm{ml} / \mathrm{min}$ in Fig. 8(b) and one can see that a more vigorous convective motion can manifestly inhibit the diffusive effect of reactant on the interface. The width of the mixing zone appears to be invariant even though the length of microchannel is lengthened three times. Hence, using a higher flow rate should be an efficient way to avoid possible fuel crossing phenomena in a longer microchannel.

The geometric design of electrode is also an important factor that might affect the cell performance. Here we consider four typical cases as shown in Fig. 9 with $\left[\mathrm{H}_{2} \mathrm{O}_{2}\right]=0.75 \mathrm{M}$ and flow rate $0.36 \mathrm{ml} / \mathrm{min}$. The corresponding polarization curves are shown in Fig. 10. As we could expect, the case (B) has the worst cell performance due to the longest distance between the two electrodes which causes the largest ohmic resistance in these four cases. For the case $(\mathrm{C})$, the total electrode surface is double of case (A), while the corresponding polarization 
(a)

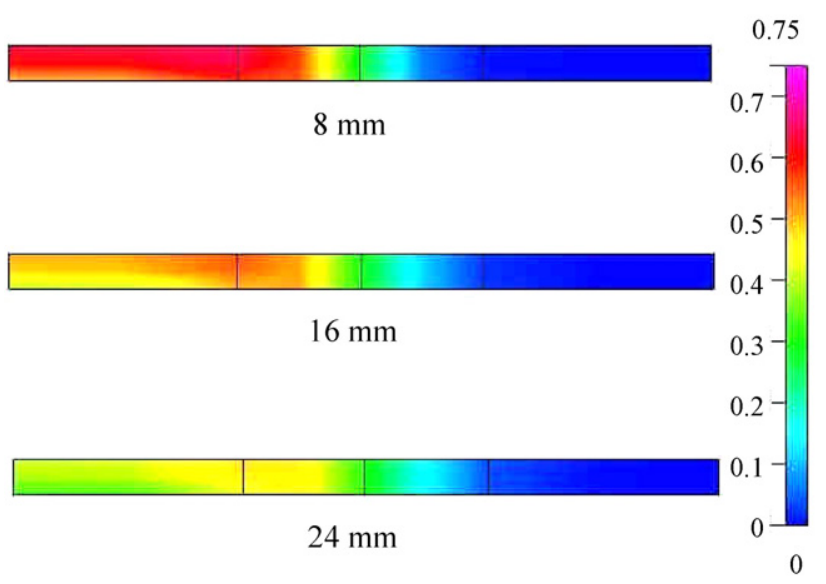

(b)

$\left[\mathrm{H}^{+}\right](\mathrm{M})$

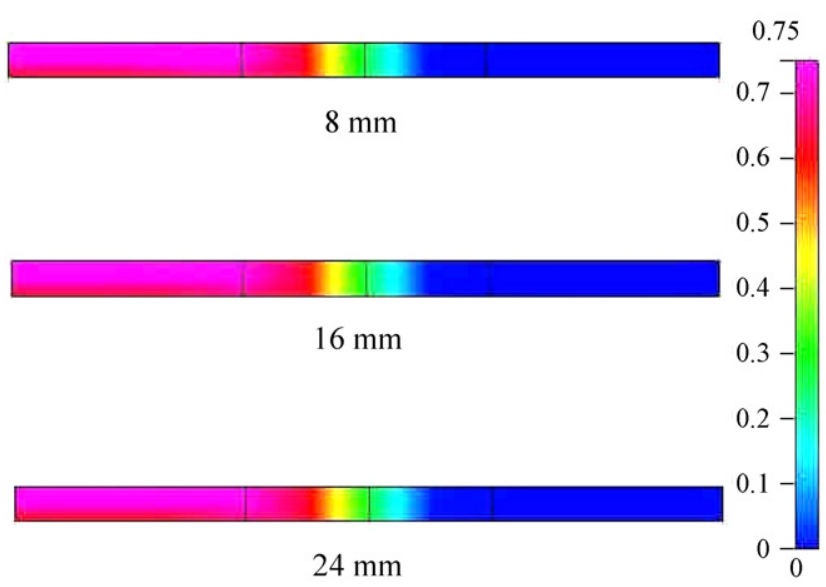

Fig. 8. The concentration contours of ion $\mathrm{H}^{+}$at the outlet of microchannel for three assigned microchannel lengths with $\left[\mathrm{H}_{2} \mathrm{O}_{2}\right]=0.75 \mathrm{M}$ and cell potential $0.3 \mathrm{~V}$ : (a) $Q=0.09 \mathrm{ml} / \mathrm{min}$ and (b) $Q=0.36 \mathrm{ml} / \mathrm{min}$.

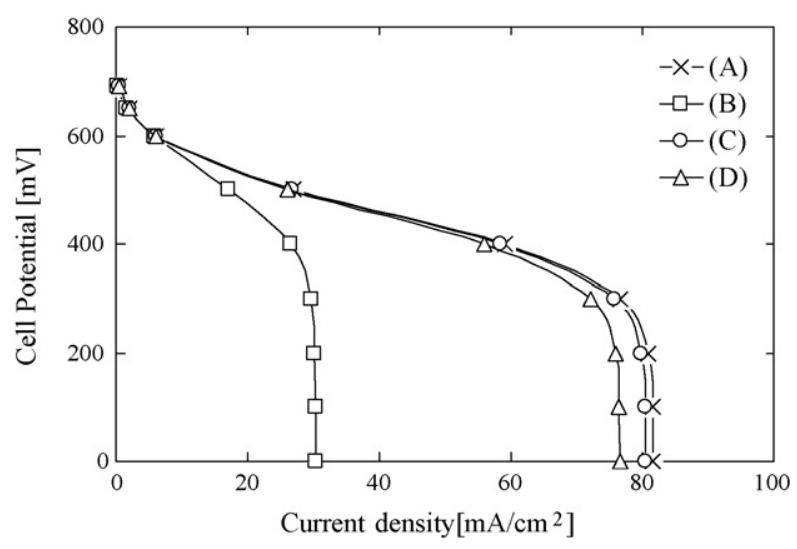

Fig. 10. The $I-V$ curves for the four typical electrode designs with $\left[\mathrm{H}_{2} \mathrm{O}_{2}\right]=0.75 \mathrm{M}$ and $Q=0.36 \mathrm{ml} / \mathrm{min}$.

curve exhibits worse performance in the region dominated by concentration losses as illustrated in Fig. 10. This phenomenon is more apparent in the case (D) with a U-shaped electrode design. The main reason could be interpreted by the concentration profiles of hydrogen peroxide at the outlet of microchannel as shown in Fig. 11. Because the flow velocity will be retarded within the boundary layer adjacent to the microchannel walls, the reactants contained in the streams will have more time to be in contact with the electrodes and make the concentration boundary layer grow gradually down the stream. This effect is more significant in the region close to the right and left lateral walls due to the overlap of concentration boundary layers. The thicker concentration boundary layer will increase the transport resistance of reactants and block them to reach the electrode surfaces. Therefore, under high load condition, the average current density of case (C) will be slightly less than that of case (A) due to the more concentration losses near the vicinity of lateral walls. This effect is more distinct in the case (D) as indicated by the depletion zones near the lateral walls, and

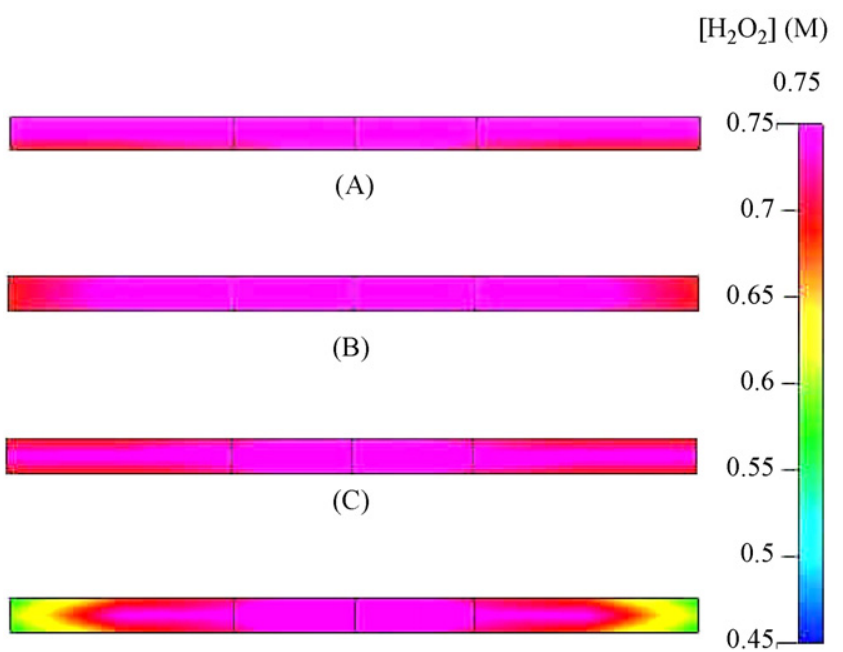

(D)
(D)

Fig. 9. The four typical designs of electrodes.

\section{(A)}

(B)

(C)

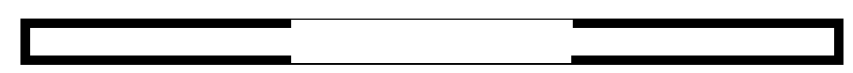




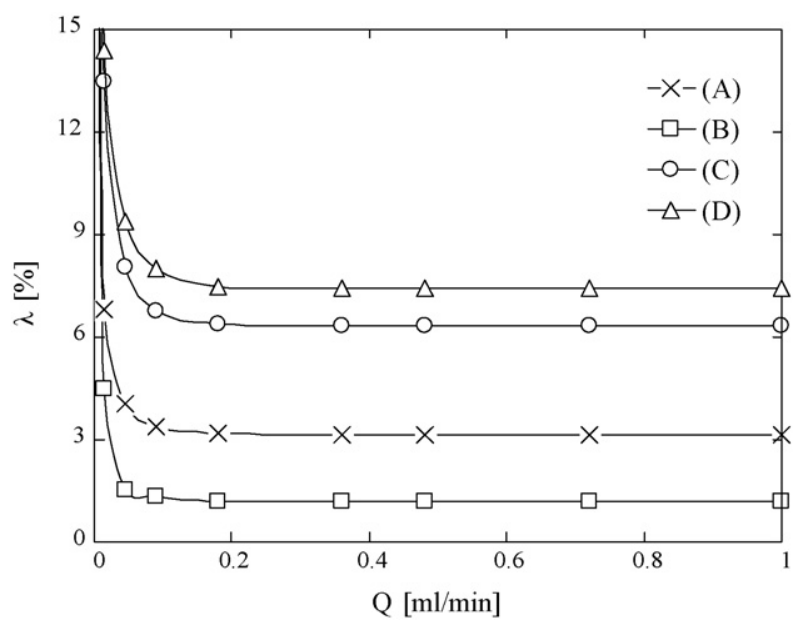

Fig. 12. The variations of consumption rate of hydrogen peroxide $\lambda$ with volumetric flow rate $Q$ for the four typical cases of electrode design with $\left[\mathrm{H}_{2} \mathrm{O}_{2}\right]=0.75 \mathrm{M}$ and $Q=0.36 \mathrm{ml} / \mathrm{min}$.

thus causes even more concentration losses as demonstrated in Fig. 10.

The corresponding consumption rates of hydrogen peroxide $\lambda$ for these four cases are shown in Fig. 12. Obviously, after the cell performance becomes invariant with the flow rate, the consumption rate is approximately in proportion to the total electrode surface. The case (D) appears to have the highest consumption rate and the consumption rate of case $(\mathrm{C})$ is about double of case (A). Hence it should be a quite efficient way to improve the consumption rate by providing more reacting surface in the electrode design. However, a higher consumption rate does not indicate that it will give a better cell performance although the total amount of current output may become larger. As presented in Fig. 10, the cell performance depends on the electrode design and a better design should possess less ohmic and concentration losses.

So far almost all researches in the literature related to membraneless microfuel cell focused on the measurement and analysis of the cell performance. External pumping devices were used to drive the reactants flowing through the microchannels for generating electricity. However, to make such a novel concept of microfuel cell be practical, the pumping system should be driven by the microfuel cell itself. Moreover, the recirculation system of reactants should be built up to produce electricity continuously. Further studies exploring the system integration as well as the subsystem design will be necessary and beneficial to construct the whole microfuel cell system.

\section{Conclusions}

A theoretical model has been developed in this study and successfully simulated the novel microfuel cell which utilizes a membraneless dual-electrolyte design with hydrogen peroxide as both reductant and oxidant. The cell performance has been examined in detail with respect to several critical system parameters. The results show that an extra high volumetric flow rate is not necessary since the cell performance tends to be invariant once the flow rate exceeds about $0.1 \mathrm{ml} / \mathrm{min}$. It is also found that the anode and cathode catalyst layers both may affect the cell performance significantly, which is quite different from the other types of membraneless microfuel cell that the performance is generally limited by the high transport resistance of reactant in the cathode stream. If the microchannel lengthens, an increase of the volumetric flow rate will be necessary to inhibit the development of mixing zone at the central interface of both streams, and also avoid the potentially fuel crossing problem. The geometric design of electrodes also plays an important role on the cell performance. Although more contact surface between electrolyte and electrode will provide more amount of current drawing from the cell, the cell performance in terms of current density may reduce due to the increase of concentration losses induced by the electrode design. This result suggests that it is vital to take the effects of ohmic and concentration losses into consideration when we try to increase the overall electrode surface of the system.

The microfuel cell system investigated in this study seems to be a good candidate for feasible application because its performance is comparable to an air-breathing DMFC without $\mathrm{CO}_{2}$ emission. Some further experimental works will be beneficial to verify the present predictions and fulfill the practical utilization in portable power sources.

\section{Acknowledgements}

The financial support for this research from National Science Council of Taiwan through the grants NSC 95-2221-E-036-051 and NSC 94-2212-E-002-008 are gratefully acknowledged.

\section{References}

[1] A. Schmitz, M. Tranitz, S. Wagner, R. Hahn, C. Hebling, J. Power Sources 118 (2003) 162.

[2] C. Chen, X. Li, T. Wang, X. Zhang, J. Li, P. Dong, D. Zheng, B. Xia, J. Microelectromech. Systems 15 (2006) 1088.

[3] S.C. Kelley, G.A. Deluga, W.H. Smyrl, Electrochem. Solid State Lett. 3 (2000) 407.

[4] S.C. Kelley, G.A. Deluga, W.H. Smyrl, AIChE J. 48 (2002) 1071.

[5] R. Ferrigno, A.D. Stroock, T.D. Clark, M. Mayer, G.M. Whitesides, J. Am. Chem. Soc. 124 (2002) 12930.

[6] E.R. Choban, L.J. Markoski, A. Wieckowski, P.J.A. Kenis, J. Power Sources 128 (2004) 54.

[7] A. Bazylak, D. Sinton, N. Djilali, J. Power Sources 143 (2005) 57.

[8] M.H. Chang, F. Chen, N.S. Fang, J. Power Sources 159 (2006) 810.

[9] E.R. Choban, P. Waszczuk, P.J.A. Kenis, Electrochem. Solid State Lett. 8 (2005) A348.

[10] E.R. Choban, J.S. Spendelow, L. Gancs, A. Wieckowski, P.J.A. Kenis, Electrochim. Acta 50 (2005) 5390.

[11] R.S. Jayashree, L. Gancs, E.R. Choban, A. Primak, D. Natarajan, J. Am. Chem. Soc. 127 (2005) 16758.

[12] J.L. Cohen, D.A. Westly, A. Pechenik, H.D. Abruna, J. Power Sources 139 (2005) 96.

[13] J.L. Cohen, D.J. Volpe, D.A. Westly, A. Pechenik, H.D. Abruna, Langmuir 21 (2005) 3544.

[14] S. Hasegawa, K. Shimotani, K. Kishi, H. Watanabe, Electrochem. Solid State Lett. 8 (2005) A119.

[15] R.S. Jayashree, D. Egas, J.S. Spendelow, D. Natarajan, L.J. Markoski, P.J.A. Kenis, Electrochem. Solid State Lett. 9 (2006) A252.

[16] F. Chen, M.H. Chang, M.K. Lin, Electrochim. Acta 52 (2007) 2506. 
[17] R.F. Ismagilov, A.D. Stroock, P.J.A. Kenis, G.M. Whitesides, H.A. Stone, Appl. Phys. Lett. 76 (2000) 2376.

[18] A.J. Bard, R. Parsons, J. Jordan (Eds.), Standard Potentials in Aqueous Solution, IUPAC, Marcel Dekker, New York, 1985.
[19] R.E. Meredith, C.W. Tobias, Conduction in heterogeneous systems, in: C.W. Tobias (Ed.), Advances in Electrochemistry and Electrochemical Engineering, vol. 2, Interscience Publishers, New York, 1962.

[20] D.R. Lide, CRC handbook of Chemistry and Physics, CRC Press, 1975. 